\title{
Relations Between the Mandibular Canal and I, II and III Angle Classes in Panoramic Radiographs
}

\author{
Relaciones entre el Canal Mandibular y Clases I, II \\ y III de Angle en Radiografías Panorámicas
}

\begin{abstract}
Raisa Zago Falkine*; Ana Cláudia Rossi"; Alexandre Rodrigues Freire*; Sidney Raimundo Figueroba**; Francisco Carlos Groppo*; Paulo Henrique Ferreira Caria* \& Felippe Bevilacqua Prado*
\end{abstract}

FALKINE, R. Z.; ROSSI, A. C.; FREIRE, A. R.; FIGUEROBA, S. R.; GROPPO, F. C.; CARIA, P. H. F. \& PRADO, F. B. Relations between the mandibular canal and I, II and III Angle Classes in panoramic radiographs. Int. J. Morphol., 32(2):449-454, 2014.

SUMMARY: To prevent injury to the inferior alveolar nerve during dental procedures, knowledge of its anatomical location and course of the mandibular canal is imperative. The aim of this study was evaluate the location on panoramic radiographs of the mandibular canal in relation to the apices of the permanent mandibular molars and base mandible, and relate the type of mandibular canal with Angle classes I, II and III. We evaluated 748 panoramic radiographs distributed according to sex and occlusal class (Angle I, II and III) of fully dentate individuals, 18-51 age group. The radiographs were divided according to Angle classes based on cephalometric tracing, clinical data from the medical records of each individual and the analysis of of the maxillar and mandibular dental arches models. The same individuals had the mandibular canal bilaterally assessed, and classified according to their location relative to the root apices of the mandibular molars and mandible base. Measurements of the distance from the mandibular canal to the apices of the teeth and mandible base were made on the Software ImageLab2000®. The intra-observer reproducibility of measurements on radiographs was assessed using the coefficient of variation ( $\mathrm{p}<0.0001)$. Data were submitted to Kruskal-Wallis test, on software BioEstat 5.0. There were statistically significant differences (Kruskal-Wallis test, $\mathrm{p}<0.0001$ ) between the occlusal classes, with the type of mandibular canal. A larger number of canals types 2 and 3 in class III individuals than in others. In conclusion, the location of the mandibular canal presents morphological changes in relation to the apices of the permanent molars, and the mandibular base according to the Angle classes I, II and III.

KEY WORDS: Mandibular canal; Mandible; Panoramic radiograph; Malocclusion; Molars.

\section{INTRODUCTION}

Malocclusions are understood as problems of growth and development that affect the occlusion of teeth (Aryatawong \& Aryatawong, 2000; Buschang \& Martins, 1998). El-Mangoury \& Mostafa (1990) found the prevalence of malocclusion worldwide, and concluded that Angle class I is the most prevalent group in the population (50 to 55\%), followed by class II (15 to $20 \%$ ) and class III (1\%). In the Brazilian population Angle class II is the most prevalent (42\%), with $74 \%$ of this class related to skeletal impairment (Reis et al., 2002).

To prevent injury to the inferior alveolar nerve during dental procedures, knowledge of its anatomical location and course of the mandibular canal is imperative. Among the many factors that can change the position of the mandibular canal, is the type of occlusion of the individual (Díaz Torres et al., 1990).
Nortjé et al. (1977) evaluated the bilateral mandibular canals in 3612 panoramic radiographs and found three distinct types of mandibular canal according to its position relative to the mandibular base, and the apices of the canals of lower molars. Liu et al. (2009) evaluated the shape and location of the mandibular canal, bilaterally, in 386 panoramic radiographs of Chinese individuals and observed that the mandibular canal showed the following shapes: linear curve (12.75\%), spoon (29.25\%), curve -elliptic arch $(48.5 \%)$, and rotation curve $(9.5 \%)$. Also the most common type of mandibular canal appeared closer to the canal apices of the third mandibular molar. Jung et al. (2007) evaluated CT scans of Korean individuals with Angle class III, and found differences in the location of the mandibular canal when compared with the Angle class I individuals. These authors concluded that the mandibular canal appeared to be lingual located more inferiorly in class III individuals than

* Department of Morphology, Anatomy Area, Piracicaba Dental School - University of Campinas - UNICAMP, Piracicaba, SP, Brazil.

** Department of Physiological Sciences, Pharmacology/Anesthesiology/Therapeutics Area, Piracicaba Dental School, University of Campinas - UNICAMP, Piracicaba, SP, Brazil. 
in individuals with class I, but a comparison of the mandibular canal location in relation to the apices of the lower molars in individuals in the Angle classes I, II and III was not performed.

Panoramic radiograph of oral region is a technique that includes in a single image, mandible, maxillae and surrounding structures (Catic et al., 1998). Its interpretation is critical in preoperative planning for implants, extractions of third molars, osteotomies, and other maxillofacial surgery; since it minimizes surgical risks, especially in the mandible (Stella \& Tharanon, 1990). Panoramic radiograph is useful to assess the location of the mandibular canal; as it enables the study of the topography of the mandibular canal in relation to the teeth, the positioning in relation to the cortical plates and the mandibular base, and its course as a whole (Tronje et al., 1981; Jung et al., 2012).

Thus, the aim of this study was to evaluate the location using panoramic radiographs of the mandibular canal in relation to the apices of the permanent mandibular molars and the mandible base, and relate the type of mandibular canal with Angle classes I, II and III.

\section{MATERIAL AND METHOD}

We evaluated 748 panoramic radiographs, and the sample was divided into the following groups: Group 1: 277 radiographs of Class I (being 145 males and 132 females); Group 2: 369 radiographs of Class II (being 171 males and 198 females) and Group 3: 102 radiographs of Class III (being 48 males and 54 females). This study was approved by the Ethics Committee of the Piracicaba Dental School UNICAMP with the approval protocol number 033/2011.

For inclusion in the sample were selected only panoramic radiographs of fully dentate individuals, showing all the healthy molars bilaterally, and with complete canal formation. Additionally, the individuals had mandibular canal unique and of the same type bilaterally, and were in the 18-51 age group. The medical record of each individual participant of the sample was evaluated and the individuals that presented a medical history of hyperparathyroidism, osteoporosis, hypo-or hyperthyroidism, diabetes, and chronic renal disease were excluded from the study. The dentate individuals showing signs of temporomandibular disorders and/or para-functional habits (such as thumb sucking and onychophagia) were also excluded from the sample.

Determination of the Angle classes. Cephalometric radiographs were used to determine the occlusal Angle classes of these individuals. Thus, radiographs were used to select individuals in a qualitative form in groups according to Angle classes I, II, III. The analysis of type of the mandibular canal was performed in panoramic radiographs.

The 748 radiographs presented the relationship maxillomandibular classified as Angle classes I, II, III. Angles classes were classified by performing angular cephalometric measurements. Furthermore, cephalometric findings were confirmed by the data obtained in the clinical records from each individual registered with the Piracicaba Dental School - UNICAMP, as well as the analysis of the maxillar and mandibular dental arches models.

In this study, the Steiner (1960) analysis was used to determine the occlusal class. The values were obtained by tracing of the angles: SNA and SNB. On SNA: S is the virtual point in the center of sella turcica, $\mathrm{N}$ is the nasion point (most anterior point of the front-nasal suture), and $\mathrm{A}$ is the deepest part of the sub-spinal concavity. In SNB: S is the virtual point in the center of the sella turcica, $\mathrm{N}$ is the nasion point (most anterior point of the front-nasal suture), and B is the deepest part of the supramentual concavity, representing the boundary between the base of the anterior region of the mandibular alveolar bone. After tracing SNA and SNB, angle ANB was obtained; it was determined that the pattern indicated by occlusion and the convexity of face (Fig. 1).

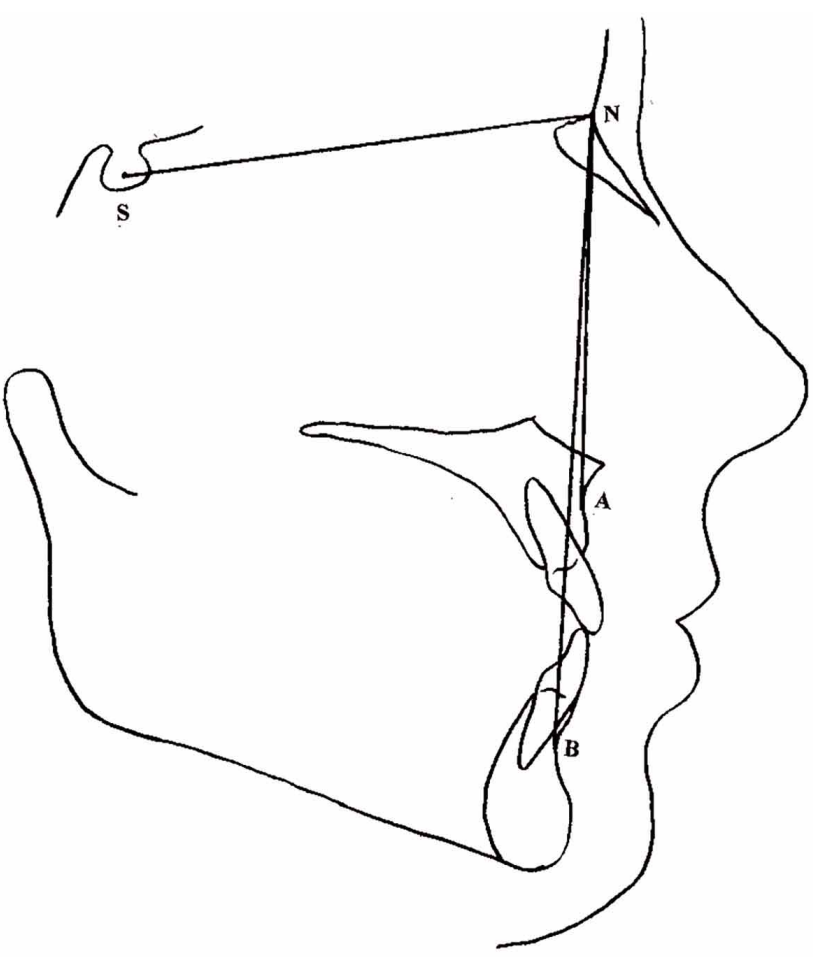

Fig. 1. Cephalometric tracing to determine the angle (ANB). 
To achieve the cephalometric tracing delimitations of the dental skeletal structures were performed, namely: anterior and posterior bases of the skull; profile of glabella and nasal bones; pterygomaxillary fissure; maxilla, mandible, upper and lower central incisors; soft profile. The tracings were made in software Imagelab2000®.

\section{Determination of the Mandibular Ca-} nal Position. Mandibular canal, bilaterally, in I, II and III Angle classes on panoramic radiographs were classified according to Nortjé et al. (1977):

1 - If the mandibular canal is in contact or is positioned at a maximum of $2 \mathrm{~mm}$ from the apex of the first, second and third permanent molars.

2 - If the mandibular canal is located halfway between the apices of the permanent molars canals, and halfway from the base of the mandible.

3 - If the mandibular canal is in contact or approaches, a maximum of $2 \mathrm{~mm}$ from the cortical bone of the mandibular base.

Measurements of the distance of the mandibular canal in relation to the apices of the teeth, and the mandibular base were performed in software ImageLab2000®.

Statistical Analysis. Intra-observer reproducibility of measurements on radiographs was assessed using the coefficient of variation ( $\mathrm{p}<0.0001)$. Data were submitted to the Kruskal-Wallis and Mann-Whitney tests, in the software BioEstat 5.0 (Mamiramuá Foundation, Belém, PA).

\section{RESULTS}

There were no differences between the proportions of the sexes regarding any of occlusal classes (Chi-square, $\mathrm{p}>0.05$ ) and mandibular canal morphology (Kruskal-Wallis, $\mathrm{p}=0.0673$ ) (Table I). No statistically significant differences were observed between sides (Mann-Whitney, 0.3509) regarding the mandibular canal morphology. The results (Table II) revealed that $88.8 \%$ of morphology matched between sides. Non-matched sides were excluded from the analysis (Fig. 2).

Figure 2 shows the distribution of the types of canal morphology among the occlusal classes. Statistically significant differences (Kruskal-Wallis test, $\mathrm{p}<0.0001$ ) were observed among occlusal classes. A higher proportion of mandibular canal types 3 and a lower rate of type 1 were found in class-III individuals when compared to class I $(\mathrm{p}=0.0314)$, and class II $(\mathrm{p}=0.0025)$. There were no significant differences $(\mathrm{p}=0.2382)$ between classes I and II regarding the morphology types were observed.

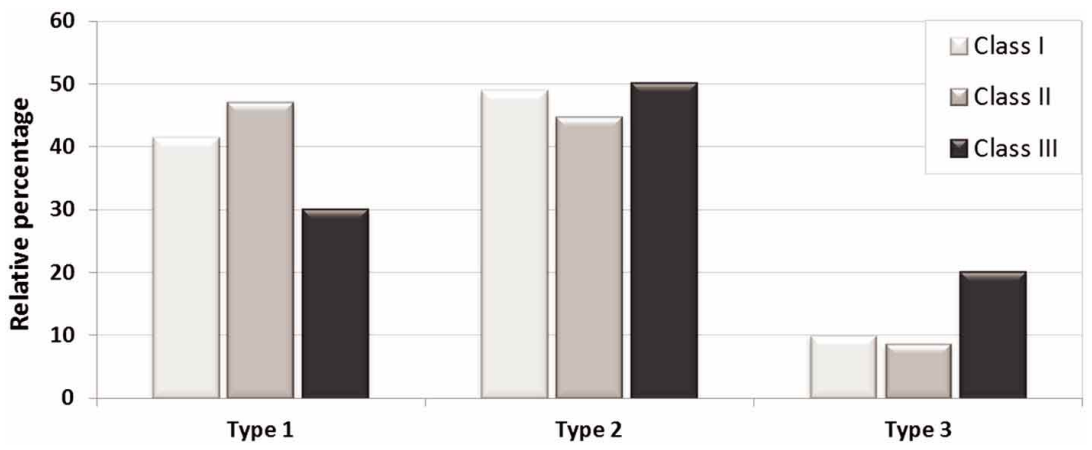

Fig. 2. Relative distribution of the mandibular canal morphological types among occlusal classes.

Table I. Relative distribution of evaluated radiographs according to gender and occlusal classes.

\begin{tabular}{lccc}
\hline & Females & Males & Total \\
\cline { 2 - 4 } Class I & $132(47.7 \%)$ & $145(52.3 \%)$ & $277(100 \%)$ \\
Class II & $198(53.7 \%)$ & $171(46.3 \%)$ & $369(100 \%)$ \\
Class III & $54(52.9 \%)$ & $48(47.1 \%)$ & $102(100 \%)$ \\
Total & $384(51.3 \%)$ & $364(48.7 \%)$ & $748(100 \%)$ \\
\hline
\end{tabular}

Table II. Relative distribution of mandibular canal types according to the side of evaluation.

\begin{tabular}{lccccc}
\hline \multirow{2}{*}{ Left side } & \multicolumn{3}{c}{ Right side } \\
\cline { 3 - 6 } & Type 1 & $285(93.8 \%)$ & Type 2 & Type 3 & Total \\
\hline \multirow{3}{*}{ Type 2 } & $26(7.6 \%)$ & $310(6.3 \%)$ & & $\mathbf{3 0 4}(\mathbf{1 0 0 \% )})$ \\
& Type 3 & $1(1 \%)$ & $30(30 \%)$ & $69(69 \%)$ & $\mathbf{1 0 0}(\mathbf{1 0 0 \% )})$ \\
& Total & $312(41.7 \%)$ & $359(48 \%)$ & $77(10.3 \%)$ & $\mathbf{7 4 8 ( 1 0 0 \% )}$ \\
\hline
\end{tabular}




\section{DISCUSSION}

In this study the panoramic radiograph was used because it is a popular and widely accepted technique to produce a single image of the facial bones and their surrounding structures. It is also possible to perform reproducibility on panoramic radiographs, because of the possibility of minimizing errors and eliminating image distortions during radiographic technique (Schulze et al., 2000). The panoramic radiographic interpretation of the mandibular canal is not facilitated by overlapping anatomical structures because the panoramic devices put the mandible as a structure that remains on the cutting plane of the device (Kambylafkas et al., 2006; Liu et al.). Interpretation must be based on recognition of its limitations known as: distortion, expansion, and by viewing a three-dimensional structure in only two planes. Within certain limits, the panoramic radiograph can be used for vertical linear measurements and morphological evaluations accurately estimated at $\pm 10 \%$ (Kim et al., 1997).

Between the apices of the third molar and the mandibular canal three types of relationships can generally be established, that must be identified prior to surgery by imaging, as these structures may be very close to or be in contact (Díaz Torres et al.). Studies on panoramic radiographs showed variations of the mandibular canal according to age, sex, race and development of the alveolar bone (Tronje et al., 1981; Wadu et al., 1997; Oguz \& Bozkir, 2002; Yamamoto et al., 2002; Ylikontiola et al., 2002; Tsuji et al., 2005), but only Jung et al. (2007) reported the location of the mandibular canal with the type of occlusal class (class III Angle) individuals. Based on the classification of mandibular canal by Nortjé et al. and a study by Jung et al. (2012), the present study evaluated the position of the mandibular canal in relation to the apices of the lower molars and related to the three classes of occlusal Angle, which so far does not exist in the scientific literature.

In this study, the occlusal class factor showed statistically significant differences (Kruskal-Wallis test, $\mathrm{p}<0.0001$ ) with relation to the mandibular canal type, with a higher proportion of mandibular canal types 2 and 3 individuals in Angle class III, fewer type 2 and 3 canals in individuals with Angle class II, and no tendency of the mandibular canal in individuals Angle class I. Jung et al. (2007) found differences in the location of the mandibular canal between Korean individuals with Angle Classes I and III using CT scanning. The present study found mandibular canals types 2 and 3 present in most individuals with Angle Class III than in the other occlusal classes. In addition, there was a lower proportion of such individuals in the mandibular canal Angle class II. Jung et al. (2007) suggested that these differences in the position of the mandibular canal occur because of changes in the positioning of the teeth in the molar region, especially in Angle class III individuals.

The present study revealed that individuals with Angle class I have not shown the tendency for a specific type of mandibular canal, considering the three types of canals evaluated, which creates difficulty in interpreting radiographic mandibular canal type in most of the world population, since this occlusal class is the most prevalent (50 to 55\%) according El-Mangoury \& Mostafa. Therefore, one can not suggest in this study the canal type greater proportion of individuals in Angle class I, but it can alert the dentist to seek 3D evaluations such as computed tomography to confirm the real placement of the mandibular canal.

Generally, Nortjé et al. reported that the mandibular canal type most commonly found in the world population is the first type and a smaller proportion of the population is the third type. In the present study, the only one to consider the occlusal class factor, we found that all three types of mandibular canal were well distributed among the groups, with no more or less a kind of incident, which probably demonstrates how the mandibular canal is influenced by mandible morphological variations and occlusal class.

The knowledge of the real position of the mandibular canal in the three occlusal classes is applied for planning surgeries of mandibular third molar, placing implants in the mandible (Li et al., 2001; Ylikontiola et al.), and also in sagittal split osteotomy of the mandibular ramus (Yamamoto et al.; Ylikontiola et al.). The results of this study will assist those planning to avoid complications during and after surgery, to determine the location of the mandibular canal.

\section{CONCLUSIONS}

Class III individuals had a higher proportion of mandibular canal types 2 and 3, Class II individuals had a higher proportion of the mandibular canal type 1 and Class I individuals tended not to have any mandibular canal. The mandibular canal type 3 is often found in individuals free of occlusal class. Finally, the knowledge of the type of mandibular canal in the region of lower molars is important to prevent the inferior alveolar nerve injury during surgical procedures.

ACKNOWLEDGMENTS. The authors are grateful to financial support of the Foundation for Research Support of the State of São Paulo (FAPESP), Brazil. 
FALKINE, R. Z.; ROSSI, A. C.; FREIRE, A. R.; FIGUEROBA, S. R.; GROPPO, F. C.; CARIA, P. H. F. \& PRADO, F. Relaciones entre el canal mandibular y clases I, II y III de Angle en radiografías panorámicas. Int. J. Morphol., 32(2):449-454, 2014.

RESUMEN: Para evitar lesiones del nervio alveolar inferior durante los procedimientos odontológicos, el conocimiento de la localización anatómica y curso del canal mandibular (CM) es imprescindible. El objetivo fue evaluar la localización del CM sobre radiografías panorámicas en relación con los ápices de los molares mandibulares permanentes y la base mandibular, relacionando el tipo de CM con las clases I, II y III de Angle. Se evaluaron 748 radiografías panorámicas distribuidas según sexo y clase oclusal (I, II y III de Angle) en individuos totalmente dentados (edad entre 18-51 años). Las radiografías fueron divididas de acuerdo a las clases de Angle según su trazado cefalométrico, datos clínicos de los registros médicos de cada individuo y el análisis de modelos de sus arcos dentarios mandibulares y maxilares. En los individuos se evaluó el CM bilateralmente y se clasificó de acuerdo a su ubicación en relación con los ápices radiculares de los molares mandibulares y base mandibular. Las mediciones de distancia desde el CM a los ápices radiculares y base mandibular se hicieron con el programa ImageLab2000®. Se evaluó la reproducibilidad intra-observador de las mediciones en las radiografías usando el coeficiente de variación $(\mathrm{p}<0,0001)$. Los datos fueron sometidos a la prueba de Kruskal -Wallis con el programa BioEstat 5.0. Se observaron diferencias estadísticamente significativas (prueba de Kruskal-Wallis, p<0,0001) entre las clases oclusales y el tipo de CM. Hubo mayor número de canales tipos 2 y 3 en los individuos clase III. La ubicación del canal mandibular presenta cambios morfológicos en relación con los ápices de molares permanentes y la base mandibular de acuerdo a las clases I, II y III de Angle.

PALABRAS CLAVE: Canal mandibular; Mandibula; Radiografía panorámica; Maloclusión; Molares.

\section{REFERENCES}

Aryatawong, S. \& Aryatawong, K. Evaluation of the inferior alveolar canal by cross-sectional hypocycloidal tomography. Implant Dent., 9(4):339-45, 2000.

Buschang, P. H. \& Martins, J. Childhood and adolescent changes of skeletal relationships. Angle Orthod., 68(3):199-206, 1998.

Catic, A.; Celebic, A.; Valentic-Peruzovic, M.; Catovic, A.; Jerolimov, V. \& Muretic, I. Evaluation of the precision of dimensional measurements of the mandible on panoramic radiographs. Oral Surg. Oral Med. Oral Pathol. Oral Radiol. Endod., 86(2):242-8, 1998.

Díaz Torres, M. J.; Guisado Moya, B. F.; Vega del Barrio, J. M.; Calatayud Sierra, J. \& Carrillo Baracaldo, J. S. Factores clínicos y radiológicos de "verdadera relación" entre el nervio dentario inferior y el tercer molar. Rev. Esp. Cir. Oral Maxilofac., 75(3):261-4, 1990.

El-Mangoury, N. H. \& Mostafa, Y. A. Epidemiologic panorama of dental occlusion. Angle Orthod., 60(3):207-14, 1990.

Jung, Y. H.; Nah, K. S. \& Cho, B. H. Correlation of panoramic radiographs and cone beam computed tomography in the assessment of a superimposed relationship between the mandibular canal and impacted third molars. Imaging Sci. Dent., 42(3):121-7, 2012.

Jung, Y. H.; Nah, K. S. \& Cho, B. H. The location of the mandibular canal in prognathic patients compared to subjects with normal occlusion. Korean J. Oral Maxillofac. Radiol., 37:217-20, 2007.

Kambylafkas, P.; Murdock, E.; Gilda, E.; Tallents, R. H. \& Kyrkanides, S. Validity of panoramic radiographs for measuring mandibular asymmetry. Angle Orthod., 76(3):388-93, 2006.
Kim, H. J.; Lee, H. Y.; Chung, I. H.; Cha, I. H. \& Yi, C. K. Mandibular anatomy related to sagittal split ramus osteotomy in Koreans. Yonsei Med. J., 38(1):19-25, 1997.

Li, N.; Zhao, B. \& Tan, C. Intramandibular course and anatomic structure of the inferior alveolar nerve canal. Zhonghua Kou Qiang Yi Xue Za Zhi, 36(6):446-7, 2001.

Liu, T.; Xia, B. \& Gu, Z. Inferior alveolar canal course: a radiographic study. Clin. Oral Implants Res., 20(11):1212-8, 2009.

Nortjé, C. J.; Farman, A. G. \& Grotepass, F. W. Variations in the normal anatomy of the inferior dental (mandibular) canal: a retrospective study of panoramic radiographs from 3612 routine dental patients. Br. J. Oral Surg., 15(1):5563, 1977.

Oguz, O. \& Bozkir, M. G. Evaluation of location of mandibular and mental foramina in dry, young, adult human male, dentulous mandibles. West Indian Med. J., 51(1):14-6, 2002.

Reis, S. A. B.; Capelozza-Filho, L. \& Mandetta, S. Prevalence of normal occlusion and malocclusion among adult, Caucasian Brazilians, with normal facial profile. Rev. Dental Press Ortodont. Ortop. Facial, 7(1):17-25, 2002.

Schulze, R.; Krummenauer, F.; Schalldach, F. \& d'Hoedt, B. Precision and accuracy of measurements in digital panoramic radiography. Dentomaxillofac. Radiol., 29(1):52-6, 2000.

Steiner, C. C. The use of cephalometrics as an aid to planning and assessing orthodontic treatment. Report of a case. Am. J Orthod., 46(10):721-35, 1960. 
Stella, J. P. \& Tharanon, W. A precise radiographic method to determine the location of the inferior alveolar canal in the posterior edentulous mandible: implications for dental implants. Part 1: Technique. Int. J. Oral Maxillofac. Implants, 5(1):15-22, 1990 .

Tronje, G.; Eliasson, S.; Julin, P. \& Welander, U. Image distortion in rotational panoramic radiography. II. Vertical distances. Acta Radiol. Diagn. (Stockh.), 22(4):449-55, 1981.

Tsuji, Y.; Muto, T.; Kawakami, J. \& Takeda, S. Computed tomographic analysis of the position and course of the mandibular canal: relevance to the sagittal split ramus osteotomy. Int. J. Oral Maxillofac. Surg., 34(3):243-6, 2005.

Wadu, S. G.; Penhall, B. \& Townsend, G. C. Morphological variability of the human inferior alveolar nerve. Clin. Anat., 10(2):82-7, 1997.

Yamamoto, R.; Nakamura, A.; Ohno, K.; \& Michi, K. I. Relationship of the mandibular canal to the lateral cortex of the mandibular ramus as a factor in the development of neurosensory disturbance after bilateral sagittal split osteotomy. J. Oral Maxillofac. Surg., 60(5):490-5, 2002.

Ylikontiola, L.; Moberg, K.; Huumonen, S.; Soikkonen, K. \& Oikarinen, K. Comparison of three radiographic methods used to locate the mandibular canal in the buccolingual direction before bilateral sagittal split osteotomy. Oral Surg. Oral Med. Oral Pathol. Oral Radiol. Endod., 93(6):736-42, 2002.
Correspondence to:

Ana Cláudia Rossi

Av. Limeira, 901 P.O. Box: 52

Department of Morphology, Anatomy Area

Piracicaba Dental School - UNICAMP

13414-903, Piracicaba, SP

BRAZIL

Email: anaanatomia@gmail.com

Received: 28-10-2013

Accepted: 30-03-2014 